\title{
Assessment of Health Literacy among Patients with Diabetes: Development of a Model for the Improvement of Health Literacy
}

\author{
Maryam Sarrafzadeh ${ }^{1}$ and Mahboobeh Kamali2,* \\ 1 Faculty of Management, University of Tehran, Tehran, Iran \\ ${ }^{2}$ Air Pollution Research Center, Iran University of Medical Sciences, Tehran, Iran \\ * Corresponding author: Mahboobeh Kamali, Air Pollution Research Center, Iran University of Medical Sciences, Tehran, Iran. Tel: \\ +989113207522; Email: kamali.lib@gmail.com; Kamali.m@iums.ac.ir
}

Received 2021 September 18; Revised 2021 September 26; Accepted 2021 October 10.

\begin{abstract}
Background: Health literacy refers to the skills and abilities people acquire, analyze, and understand regarding basic health information and services they need so that they can contribute to their health issues and make the right decision.

Objectives: Moreover, given the importance of diabetes in the world and in Iran, as well as the impact of health information literacy on the quality of life and control of diabetes, this study aimed to evaluate health information literacy of type 2 diabetic patients and design an information service model for promoting their health information literacy.

Methods: In this study, semi-structured interviews were used to collect the qualitative data needed to present the model. In the qualitative method, semi-structured interviews were conducted with 14 health literacy experts selected through purposive sampling. The Grounded Theory method was then used for analyzing interviews and explaining related dimensions and components.

Results: In total, five categories (nutritional factors, media development, physical activity, inclusive education, as well as racial and age consciousness) and a core category of "type 2 diabetes recognition" were identified in this study.

Conclusion: It was found that diabetes type 2 was heavily influenced by lifestyle and education factors. Finally, according to the interviews, a model was developed to improve the health literacy of diabetic patients.
\end{abstract}

Keywords: Health literacy, Information literacy, Information service model, Type 2 diabetes mellitus

\section{Background}

Information literacy, as a necessity in the information age, can equip people with the capabilities of recognizing the need for information, as well as locating, evaluating, and using the needed information effectively, thereby guaranteeing their survival and success to a great extent. To develop these capabilities at the community level, librarians, professors and educators, technology professionals and some policymakers have emphasized the need for teaching information skills at all levels of education and preparing individuals for lifelong learning (1). In the last decade, there has been a growing tendency toward information literacy mainly due to the relationship created between information literacy skills and lifelong learning. It is believed that people cannot find the right path without information literacy. Furthermore, professors' awareness about their roles in teaching information literate students is increasing rapidly (2).

Health literacy enables individuals to manage their health and make health-related decisions. Health literacy includes knowledge, motivation, and competence in accessing, comprehending, evaluating, and using health information for decision making (3). Low health literacy is associated with various adverse health outcomes and inappropriate use of health services. These outcomes include increased number of hospital admissions, excess emergency department use, high rates of medication use, decreased ability for proper use of medicine, poorer ability to understand health messages and instructions on medication labels, and poor selfreported health status (4).

Diabetes is a major global health problem. According to the International Diabetes Federation estimates, 425 million people were living with diabetes worldwide in 2017, and the number is projected to rise to 629 million by 2045 (5). The majority of people with diabetes (90\%) have type 2 diabetes mellitus (6). People diagnosed with diabetes need to make health care decisions daily and undertake self-management activities to manage their disease. The fact is that about $95 \%$ of diabetes selfcare activities are undertaken by people with type 2 diabetes (7). Patients with type 2 diabetes and limited health literacy often may not be able to read prescription drug labels accurately and may take prescribed medication incorrectly, may not understand the consent form, and generally have difficulty understanding the instructions for follow-up self-care and reading medical advice or warnings (8).

Information problem-solving: The Big Six Skills approach is one of the models related to health information literacy that has been widely used in the 
United States for training information skills. This sixstep model is a general approach to information problem-solving. The six steps include task definition, information seeking strategies, location and access, use of information, synthesis, and evaluation that are required for successful problem solving although the order of these six steps may vary in different situations (9).

During the three decades of health literacy development, much research has been conducted on how health literacy affects people's health. These studies have investigated health literacy as a variable affecting health status, treatment outcomes, and the physician-patient relationship. Improvement of health literacy makes it easier for diabetics to understand information on dietary, insulin injections, and glycemic control. On the other hand, health literacy plays a vital role in facilitating illness acceptance. Improved health literacy can lead to the behavioral changes required for active participation in treatment. Therefore, many researchers have investigated the association of health literacy with awareness of diabetes conditions and treatments (10-12).

The results of the studies on the association of health literacy with awareness of disease conditions and treatments show that patients with higher levels of health literacy are more aware of disease conditions and treatments (11). Luo et al. conducted a study in 2018 entitled "Validation of combined health literacy and numeracy instrument for patients with type 2 diabetes". A total of 102 samples were selected from an academic medical center in the United States, and it was concluded that the combined scale was valid (13). In 2018, Shiyanbola et al. performed a study on the association of health literacy with illness perceptions, medication beliefs, and medication adherence among individuals with type 2 diabetes. The results indicated that patients' health literacy should be assessed before medication interventions to resolve their concerns about their treatments and medications (14).

\section{Objectives}

Therefore, this study aimed to answer the question of what categories are effective in reducing and increasing the various components of health literacy that ultimately lead to specific behavioral actions in individuals.

\section{Methods}

The Grounded theory, which is used for conducting qualitative research and involves coding texts and theorizing, was utilized in the present study. The interviews were conducted with health literacy experts selected through snowball purposive sampling. The saturation point was reached after interviewing 14 experts who were familiar with diabetes, information networks, and designing health information models. The participants in the study included researchers, specialist physicians, and librarians.

\subsection{Data collection procedure}

The interview data collection method was used in the present study. First, interview questions on health information literacy promotion were designed using theoretical foundations and research literature to identify the dimensions and components affecting the promotion of health information literacy during the interviews.

In addition, the questions were modified after visiting health professionals. Subsequently, experts, professors, research consultants, and Ph.D. candidates familiar with qualitative research and health literacy validated the questions in terms of whether they could obtain the basic information from the respondents. The questions are listed in Table 1.

\subsection{Research process}

Data analysis and coding (open coding, axial coding, and selective coding) were performed after data collection. In total, 76 sub-categories and 7

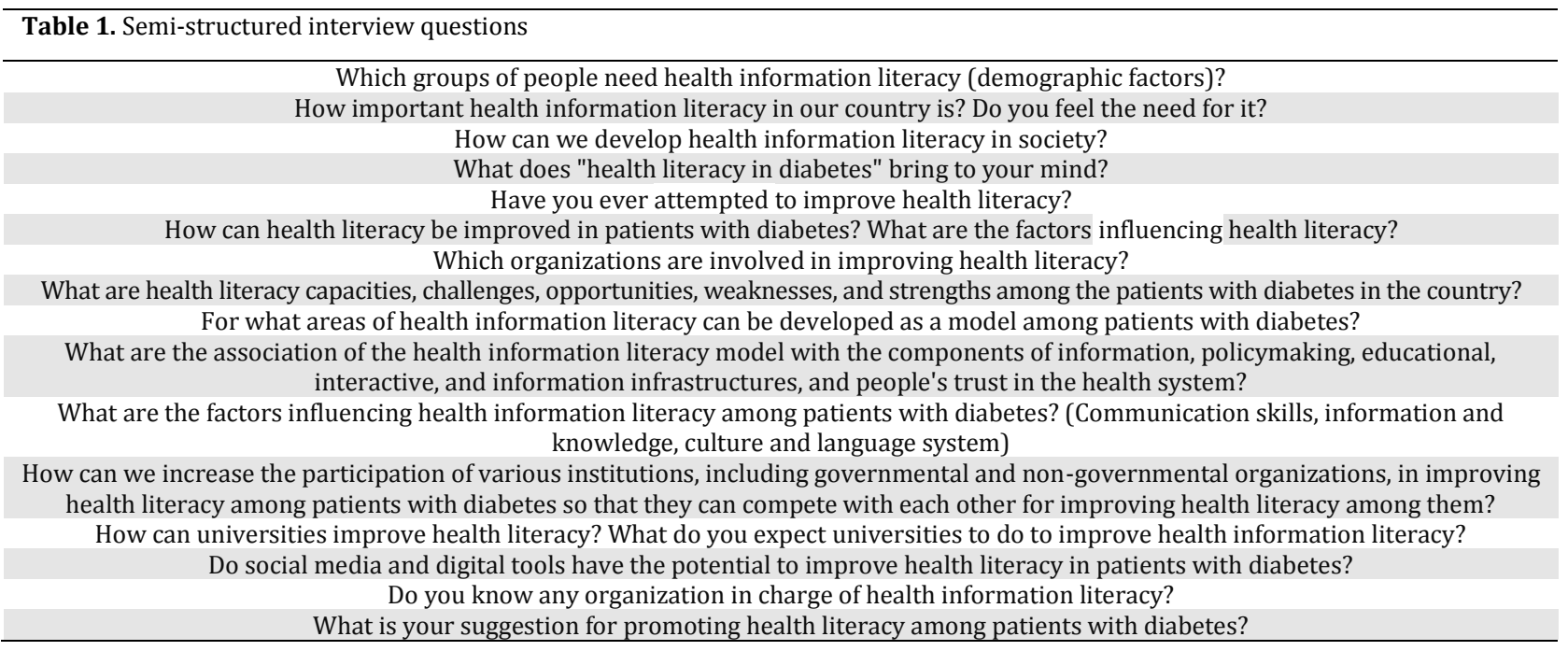


Table 2. Participants' level of education

\begin{tabular}{lc}
\hline Number & Sub-characteristics \\
\hline $\mathbf{3}$ & $\mathrm{PhD}$ \\
$\mathbf{2}$ & Clinical PhD \\
$\mathbf{5}$ & Masters' degree \\
$\mathbf{1}$ & General Practitioner \\
$\mathbf{3}$ & Bachelor's degree \\
$\mathbf{1 4}$ & Total \\
\hline
\end{tabular}

major categories were extracted from the raw data. The Grounded Theory was used to analyze the qualitative data. Table 2 tabulates the educational level of the respondents.

\subsection{Qualitative data analysis}

The Grounded Theory includes data collection, systematic data analysis, and production of knowledge. The theory developed based on the Grounded Theory will be reliable if the collected data is evidence-based. This method was used in the present study to find the model of health literacy information in patients with type 2 diabetes mellitus based on health literacy levels and other factors affecting health literacy information.

\subsection{Conceptualization process (open coding)}

Coding is a process in which data is segmented into meaningful units which can be used at the beginning of the study. The main purpose of open coding is to conceptualize and label data. Coding leads to orientation prior to selection and transforms the data into analytical meaningful units. The ways to examine raw data and do open coding include the analysis of initial interview transcripts and observations, coding of sentences and paragraphs (finding the main idea of paragraphs or sentences and analysis of the whole document), as well as observation or interviewing and questioning. Table 3 displays the concepts collected from the interviews.

\subsection{Axial coding process (major categories)}

Nutritional factors, media development, physical activity, inclusive education, age, and racial consciousness were determinants of health literacy level among people with type 2 diabetes (Table 4).

Examples of what participants said about the factors affecting type 2 diabetes mellitus are listed below.

\begin{tabular}{|c|c|c|c|c|c|}
\hline 1 & Eating habits & 19 & Propaganda & 37 & Smoking \\
\hline 2 & Unhealthy diet & 20 & Media hegemony & 38 & Alcohol abuse, addiction \\
\hline 3 & Life style & 21 & Fake news & 39 & Hookah smoking \\
\hline 4 & Nutrition literacy & 22 & Media abuse & 40 & Uncontrolled stress \\
\hline 5 & Vitamin deficiency & 23 & Aerobic exercises & 41 & Psychological stress \\
\hline 6 & Obesity & 24 & Appropriate exercise & 42 & High-Risk behavior \\
\hline 7 & Body fat & 25 & Participation in group exercises & 43 & Adolescence \\
\hline 8 & Overeating & 26 & Primary prevention via exercise & 44 & Hookah addiction \\
\hline 9 & Consumption of sweets & 27 & Secondary prevention & 45 & Opium use \\
\hline 10 & Overeating & 28 & Sports counseling & 46 & Air pollution \\
\hline 11 & Low literacy & 29 & Sports knowledge and information & 47 & Geographical location \\
\hline 12 & Incomplete information & 30 & Physical activity & 48 & Heredity \\
\hline 13 & Yellow publications & 31 & Public sports & 49 & Genealogy \\
\hline 14 & Information influx & 32 & Exercise commitment & 50 & Genetic awareness \\
\hline 15 & Non-professional training & 33 & Media advertising & 51 & Aging \\
\hline 16 & Cyberspace & 34 & Stimulus-recognition & 52 & Old age \\
\hline 17 & False news & 35 & Trauma & & \\
\hline 18 & Contradictory information & 36 & Medicines & & \\
\hline
\end{tabular}

\begin{tabular}{|c|c|c|}
\hline Row & Major categories & Subcategories \\
\hline 1 & Nutritional factors & $\begin{array}{c}\text { Eating habits, unhealthy diet, lifestyle, nutrition literacy, vitamin deficiency, obesity, body fat, } \\
\text { overeating, sweets consumption, overeating, low literacy }\end{array}$ \\
\hline 2 & Media contradiction & $\begin{array}{l}\text { Incomplete information, yellow publications, information influx, non-professional training, cyberspace, } \\
\text { false news, propaganda, media hegemony, fake news, media abuse, contradictory information }\end{array}$ \\
\hline 3 & Physical activity & $\begin{array}{l}\text { Appropriate exercise, participation in group exercises, primary prevention via exercise, secondary } \\
\text { prevention, sports counseling, sports knowledge and information, physical activity, public sports, } \\
\text { exercise commitment, media advertising, stimulus recognition, aerobic exercise }\end{array}$ \\
\hline 4 & High-risk lifestyle & $\begin{array}{l}\text { Smoking, alcohol abuse, addiction, hookah smoking, uncontrolled stress, psychological stress, high-risk } \\
\text { behaviors, adolescence, hookah addiction, opium use, air pollution, trauma, medicines }\end{array}$ \\
\hline 5 & $\begin{array}{l}\text { Age and racial } \\
\text { consciousness }\end{array}$ & Genealogy, genetic awareness, aging, old age, geographical location, heredity \\
\hline
\end{tabular}

\section{Results}

\subsection{Nutritional factors}

Diabetes and obesity are closely linked; therefore, obesity is considered the major risk factor for type 2 diabetes. The prevalence of diabetes has increased significantly along with obesity in the last 50 years. In 1985, diabetes affected 30 million people that were increased to 285 million in 2010. Hyperglycemia can lead to complications, such as heart disease, stroke, 
and diabetic retinopathy that affect eyes, kidney failure, and limb ischemia, which can lead to amputations. Diabetic ketoacidosis is an acute complication of type 1 diabetes with low prevalence (15). Nutrition and its great importance have been mentioned by the interviewer in all of the interviews .

\subsubsection{Participant: (Code 1)}

..."to me, type 2 diabetes can be caused by lifestyle, lack of physical activity, or poor diet. The prevalence of type 2 diabetes is closely related to industrialization, improved nutrition, and increased life expectancy. Industrialization has led to changes in the production, storage, and distribution of food products, leading to an increase in high-calorie foods high in fats. Increased use of saturated fats and decreased use of dietary fiber intake can lead to impaired glucose tolerance and low insulin sensitivity ."

\subsubsection{Participant: (Code 3)}

..."most people with type 2 diabetes and high blood sugar levels may have fewer food choices. Healthy eating can prevent the incidence or worsening of the disease. I'm sure eating cheese, apples, and yogurt and reducing red meat and potato consumption can improve people's health and prevent type 2 diabetes. In addition, people with type 2 diabetes should avoid eating sweets and chocolate. These patients can live long and protect themselves from the complications of this disease including heart and kidney disease, diabetic ulcers, heart attacks, strokes, and blindness by following some nutrition tips, avoiding diet breaks, going for regular checkups, and learning new methods of treatment and management of the disease."

\subsubsection{Participant: (Code 8)}

..."to me, type 2 diabetes is one of the most common non-communicable diseases spreading in the country. Failure to control the disease may lead to irreversible outcomes. Therefore, self-care plays an important role in the management of diabetes. This means that individuals can control their diabetes through diet and physical activity. It is interesting to know that it's important to control blood sugar levels. You can prevent blood sugar spikes by eating healthy foods."

\subsection{Media contradictions}

Media technology is among the most important tools used for interventions and prevention of diseases (16). The concept of media contradictions extracted from the interviews indicated that modernday media can both improve a person's performance and ability to prevent the disease and mislead the audience via false advertisements.

\subsubsection{Participant: (Code 11)}

..."I think health care providers want to learn how to use e-mail, Facebook, text messages, and websites to improve their communication skills with patients through these channels. Direct electronic communication with patients who are in a specific stage of care or treatment is not yet common. Health care is still in its infancy. Health care providers can play a role in completing health care tools. This can be very helpful for patients with type 2 diabetes both in the treatment process and even before the onset of the disease."

\subsubsection{Participant (Code 12)}

..."in the age of the Internet, change is inevitable, and the structures of health systems will be likely changed in the future. As a result, a new information technology market will be developed that can improve therapist-patient communication and contribute to medical institutions delivering healthcare services. Social media can have a big impact on patient treatment, and the raised question is what role do the health care personnel play in using this technology, and do doctors and nurses have a say in the use of technology"?

\subsection{Physical activity}

Research has shown that in addition to diet and medication, exercise is one of the major diabetes treatments. Many people with type 2 diabetes can control their blood sugar levels through diet, exercise, weight loss, and using diabetes medications. Diet and exercise play a central role in the management of diabetes (17). People with diabetes can control blood sugar levels by balancing physical activity and food.

\subsubsection{Participant (Code 5)}

..."most people are exposed to a lot of stress in daily life which has profound effects on their body and mind in the long run. The effects of exercise on the hormonal system, diabetes, neurotransmitters, and the chemical composition of blood can modulate the body's responses to external stress. Regular exercise causes happiness because drug-like substances are produced in the brain. Exercise slows aging, reduces the risk of osteoporosis and low back pain, and helps you fall asleep easier."

\subsubsection{Participant (Code 2)}

..."blood sugar levels may drop immediately after or even 6-10 hours after exercise in people with diabetes who take insulin. The physician may reduce units of pre-meal regular insulin for those who exercise for more than an hour in the morning and $\mathrm{NPH}$ insulin for those who exercise for more than an hour in the evening ."

\subsubsection{Participant (Code 7)}

..."regular physical activity contributes to weight loss, maintaining a healthy weight, controlling blood 
sugar levels, improving the body's ability to use insulin, reducing the need for medication and insulin injections, heart health, and lowering high blood pressure and high cholesterol. Those who are genetically susceptible to developing type 2 diabetes should prevent the disease by controlling diet and getting regular exercise as it has worked to a great extent. Timely information and common knowledge can contribute to preventing the onset of disease ."

\subsection{High-risk lifestyle}

High-risk behaviors are among the most serious threats to health that have been considered by health organizations, law enforcement officers, and social policymakers as one of the most important problems in society. Global studies have shown that most high-risk behaviors, including smoking, alcoholism, and tobacco use, begin before the age of 18 (18). Recent studies have shown that smoking is significantly associated with abdominal obesity. Smoking is also associated with diabetes since smoking reduces fasting insulin levels and increases blood sugar levels after eating glucose. In addition, chronic or prolonged psychological and social stress, as well as physical stress and trauma can be mentioned as the factors associated with the development of type 2 diabetes (19).

\subsubsection{Participant (Code 14)}

..."smokers are not diabetics. However, the pancreas needs to produce more insulin than it would normally need to regulate blood sugar levels, and this can lead to the development of type 2 diabetes. Smokers' insulin resistance may be due to nicotine; however, other chemicals in tobacco smoke are also associated with insulin resistance. I think, besides nicotine, other chemicals in tobacco smoke are risk factors for cancer and atherosclerosis. Tobacco is a complex mixture of more than 4,000 chemical compounds. I should mention that 50-60 of these compounds are carcinogenic and play a role in the development of diabetes."

\subsubsection{Participant (Code 11)}

..."diabetes is harder to control in smokers, compared to non-smokers. But the good news is that smokers with diabetes who have quit smoking can control their blood sugar as easily as non-smokers can. Among diabetics, smoking increases the risk of complications (such as eye problems, damage to the nerves, kidney disease, heart disease, stroke, and atherosclerosis). The more cigarettes you smoke and the more years you smoke, the greater the risks of the complications. You should control your blood sugar and quit smoking to reduce these risks."

\subsubsection{Participant (Code 6)}

.."alcohol intake increases the risk of hypoglycemia in people with diabetes. The risk of hypoglycemia may last up to 24 hours after drinking alcohol. Alcohol consumption can put you at risk for hypoglycemia by keeping your liver from releasing enough glycogen (glycogen is the storage form of glucose in the liver and muscles that can quickly supply blood sugar if needed). In addition, alcohol consumption induces loss of consciousness and reduces the person's ability to control diabetes and recognize hypoglycemia. Alcohol consumption is very harmful to people with diabetes due to long-term effects on the liver. Alcohol interferes with the liver's response to glucagon injected for treating alcoholinduced hypoglycemia. Drug-induced diabetes or impaired glucose tolerance have also been studied and approved."

\subsection{Age and age consciousness}

Diabetes mellitus refers to a group of metabolic disorders and metabolic diseases characterized by chronic hyperglycemia, caused by impaired insulin secretion/action. Although old age, obesity, family history of diabetes, a past medical history of gestational diabetes, malnutrition, and lack of physical activity are the major risk factors for this disease, a higher prevalence of diabetes has been observed in some races, including Pima Indians, Caucasians, and Mexican Americans (20).

\subsubsection{Participant (Code 3)}

..."having a parent with type 2 diabetes increases the risk of developing diabetes, and the person has a $40 \%$ chance of developing it if both parents have the disease. People with a family history of diabetes are five times more likely to develop diabetes."

\subsubsection{Participant (Code 4)}

..."the use of family history as a useful screening tool for the detection of diabetes is recommended. Family history is often closely associated with an increased risk of developing type 2 diabetes. I think a positive family history of type 2 diabetes is also a risk factor for coronary heart disease and atherosclerosis. Therefore, family history of diabetes should be considered, and other members of the family should be informed of because family history is a significant predictor of diabetes."

\subsection{Process of building and presenting the Grounded Theory (selective coding)}

Selective coding is the process of selecting the core category and relating it to the other categories, validating these relationships, and filling in categories that need further refinement and development. The core category integrates all other categories to explain the whole data (21).

The categories that need further refinement and development must also be filled in. In other words, in the selective coding phase, the categories are integrated into one cohesive theory. In this phase, the researcher, according to his understanding of the text 
of the phenomenon under study, either presents the framework of the paradigm model narratively or breaks down the paradigm model and presents the final theory in a graphic way.

It is believed that this core concept always exists. In particular, selective coding is the process of selecting the core category and linking it to other categories, validating the relationships, and filling in the blanks with categories that need further refinement and expansion (22). Accordingly, type 2 diabetes recognition was selected as the core category and considered the closest category to other categories defined based on the objective of the research (Figure 1).



Figure 1. Type 2 diabetes recognition: Promotion of health literacy

\section{Discussion}

Health literacy is defined as a wide range of knowledge and skills in accessing, processing, understanding, and applying health information (23). Many unpleasant health-related outcomes result from inadequate health literacy. Inadequate health literacy is associated with poor adherence to medication and failure to follow medical instructions, poorer glycemic control, limited health knowledge, less participation in treatment decision making, fewer health concerns, and poor patientphysician communication. This study aimed to assess health information literacy among patients with type 2 diabetes and identify information components and design an information service model for promoting their health information literacy.

Although many experts believe that patients and their families have a major responsibility to manage diabetes, and empowering patients to manage diabetes through self-care is one of the important goals for diabetes control (19), many factors affect diabetes. The data obtained from this qualitative study on the views of experts indicated that patients are usually provided with incomplete information, and in many cases, they are confused by exposure to conflicting information from different sources, especially information gained from the media. Media is one of the most important tools for disease prevention and health promotion interventions. Social media can be used for creating or sharing content contributing to personal and social development (24). The interview transcripts also showed the great impact of the media on health literacy levels .

The results of the present study indicated that the use of health information technology leads to health equity and improved health care providerpatient communication. Health information technology can contribute to scheduling appointments, prescription renewal, patient access to laboratory test results, and answering questions. This is consistent with the results of a study conducted by Fok indicating that $72 \%$ of American physicians have adopted email communication with patients, and $48 \%$ of them believe that their patients are satisfied with this method of communication; moreover, $50 \%-80 \%$ of patients search the Internet for information about their health and treatment status before an encounter with the provider, and $75 \%$ of the cases use e-mail for consulting their doctors (25).

Therefore, some IT Infrastructures are required to improve health literacy and the patient-physician relationship. For this purpose, in addition to education, accessibility to the Internet, social media messaging apps, as well as non-governmental social associations and institutions are essential for exchanging ideas and feelings. Generally, chronic 
diseases, including diabetes, are accompanied by various clinical, social, and psychological problems, which in turn limit the physical and mental activities of individuals. This study showed that insufficient health literacy and general poor health status are common problems, and diabetic patients need more education to improve the level of health literacy and their general health status .

Based on the Information Problem Solving (the big Six Skills Approach) and data collected from the interviews in this qualitative research, the model for health information literacy among the patients with type 2 diabetes was outlined as described below:

The final model for promoting health literacy in patients with type 2 diabetes: (This model is shown schematically below.)
1. Information infrastructures:

- Disease information management

- Building IT infrastructure

- Access to information with no time and place restrictions

- Possibility of correcting disease information

Existence of a database

2. Problem definition (content):

- Definition of type 1 diabetes

- Definition of type 2 diabetes

3. Cause of the disease outbreak:

- Genetic risk factors

- Lifestyle-related risk factors

4. Prevention and management factors :

- Genetic protective factors

- Lifestyle-related protective factors

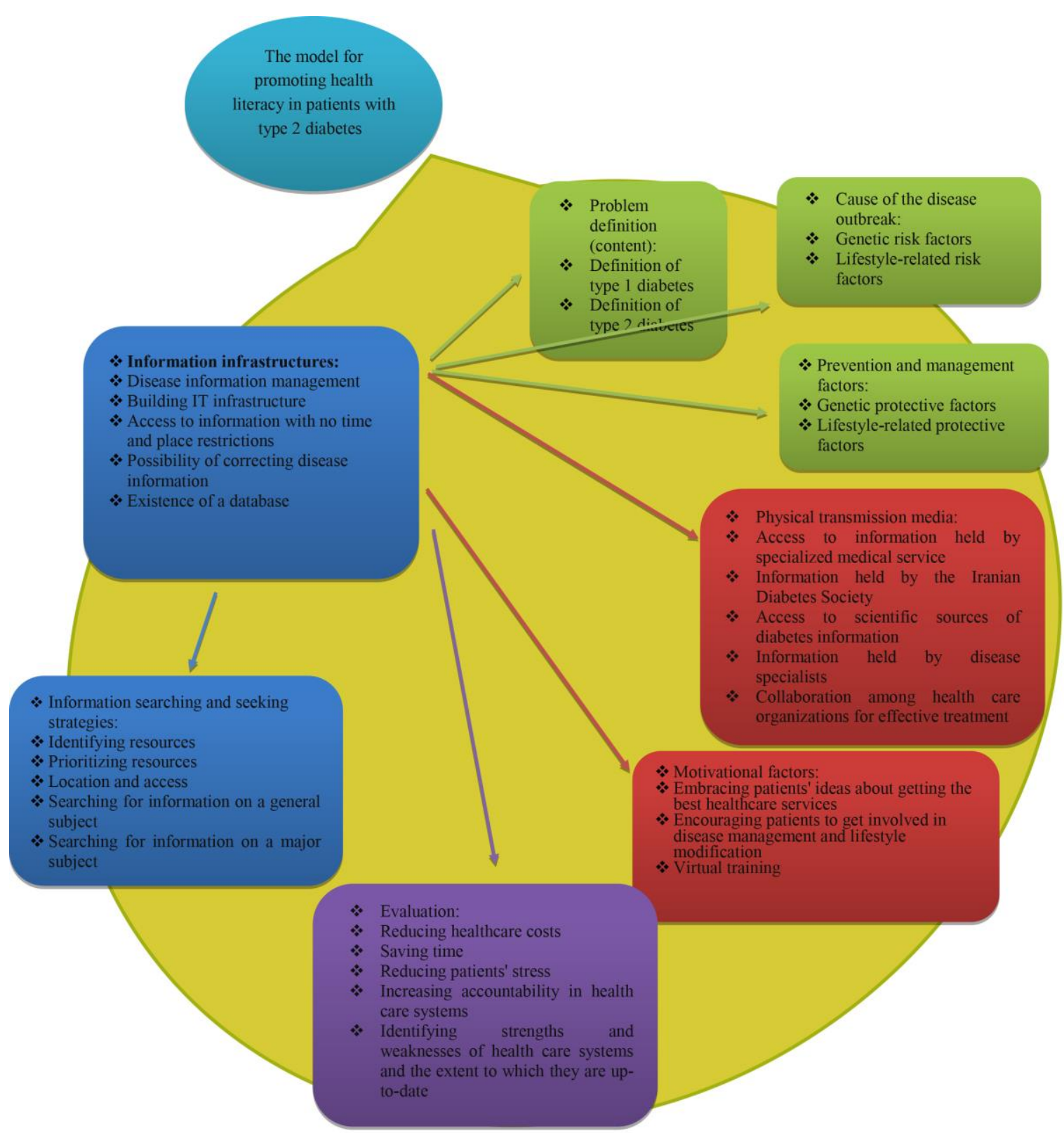


5. Physical transmission media:

- Access to information held by specialized medical service

- Information held by the Iranian Diabetes Society

- Access to scientific sources of diabetes information

- Information held by disease specialists

- Collaboration among health care organizations for effective treatment

6. Motivational factors:

- Embracing patients' ideas about getting the best healthcare services

- Encouraging patients to get involved in disease management and lifestyle modification

- Virtual training

- Evaluation:

- Reducing healthcare costs

- Saving time

- Reducing patients' stress

- Increasing accountability in health care systems

- Identifying strengths and weaknesses of health care systems and the extent to which they are upto-date

7. Information searching and seeking strategies:

- Identifying resources

- Prioritizing resources

- Location and access

- $\quad$ Searching for information on a general subject

- Searching for information on a major subject

- According to this model, a person with high health information literacy can

- Determine and prioritize the range of information needed;

- Access needed information effectively and efficiently;

- Evaluate the information and its sources critically and incorporate selected information in his/her knowledge base and value system;

- Use information effectively to accomplish a specific purpose;

- Use acquired information considering the medical and legal restrictions.

The model's performance can be defined by the following indices:

Performance Index One: A diabetic information literate person identifies and explains the need for information. Performance Index Two: A patient with type 2 diabetes identifies a wide range of different potential sources of information.

Performance Index Three: A patient with type 2 diabetes considers the costs and benefits of locating and accessing needed information.

Performance Index Four: A patient with type 2 diabetes re-evaluates the nature and extent of the information needed.

\section{Acknowledgments}

The authors would like to express their sincere gratitude to all participants in the study.

\section{Footnotes}

Authors' contributions: The first author is Maryam Sarrafzadeh, and the corresponding author is Mahboobeh Kamali.

Ethical Approval: None.

Funding/Support: No specific funding has been provided for the research.

Conflicts of Interest: The authors declare that they have no competing interests.

Informed Consent: none.

\section{References}

1. Rader HB. Information literacy-an emerging global priority. White paper prepared for UNESCO, the US National Commission on Libraries and Information Science. 2002; 12:02-15

2. Feast V. Integration of information literacy skills into business courses. Reference services review. 2003. doi: 10.1108/00907320310460942

3. Sørensen K, Van den Broucke S, Fullam J, Doyle G, Pelikan J Slonska Z, et al. Health literacy and public health: a systematic review and integration of definitions and models. BMC public health. 2012;12(1):1-13. doi: 10.1186/1471-2458-12-80. [PubMed: 22276600].

4. Panahi R, Osmani F, Sahraei M, Ebrahimi S, Shamsizadeh Nehadghashti M, Javanmardi E. Relationship of health literacy and quality of life in adults residing in Karaj, Iran. J Educ Community Health. 2018;4(4):13-9. doi: 10.21859/jech.4.4.13

5. Federation ID. IDF diabetes atlas 8th edition. International Diabetes Federation. 2017:905-11.

6. Holman N, Young B, Gadsby R. Current prevalence of Type 1 and Type 2 diabetes in adults and children in the UK. Diabetic medicine: a journal of the British Diabetic Association. 2015;32(9):1119-20. doi: 10.1111/dme.12791. [PubMed: 25962518]

7. Krichbaum K, Aarestad V, Buethe M. Exploring the connection between self-efficacy and effective diabetes self-f management. The Diabetes Educator. 2003;29(4):653-62. doi: 10.1177/014572170302900411. [PubMed: 13677176].

8. Bailey SC, Brega AG, Crutchfield TM, Elasy T, Herr H, Kaphingst K, et al. Update on health literacy and diabetes. The Diabetes Educator. 2014;40(5):581-604. doi: 10.1177/0145721714 540220. [PubMed: 24947871].

9. Eisenberg MB, Berkowitz RE. Information Problem-Solving: The Big Six Skills Approach. School Library Media Activities Monthly. 1992;8(5):27.

10. Afshari M, Khazaei S, Bahrami M, Merati H. Investigating adult health literacy in Tuyserkan city. J Educ Community Health. 2014;1(2):48-55. doi: 10.20286/jech-010248.

11. Ahmadi F, Mehrmohammadi M, Montazeri A, Vella J. Health Literacy and Teacher Education. The Journal of New Thoughts on Education. 2018;14(1):7-30. doi: 10.22051/jontoe.2018. 13734.1648.

12. Borji M, Tarjoman A, Otaghi M, Salimi E, Naseri A. Health literacy level and its related factors among the elderlies in Ilam in 2015. Iran Journal of Nursing. 2017;30(108):33-43. doi: 10.29252/ijn.30.108.33.

13. Luo H, Patil SP, Wu Q, Bell RA, Cummings DM, Adams AD, et al. Validation of a combined health literacy and numeracy instrument for patients with type 2 diabetes. Patient education and counseling. 2018;101(10):1846-51. doi: 10.1016/j.pec.2018.05.017. [PubMed: 29805071].

14. Shiyanbola OO, Unni E, Huang Y-M, Lanier C. The association of health literacy with illness perceptions, medication beliefs, and medication adherence among individuals with type 2 diabetes. 
Research in Social and Administrative Pharmacy. 2018; 14(9):824-30. doi: 10.1016/j.sapharm.2017.12.005. [PubMed: 29317189].

15. Chinenye S, Uloko AE, Ogbera AO, Ofoegbu EN, Fasanmade OA, Fasanmade AA, et al. Profile of Nigerians with diabetes mellitus-Diabcare Nigeria study group (2008): Results of a multicenter study. Indian journal of endocrinology and metabolism. 2012;16(4):558. doi: 10.4103/2230-8210.98011. [PubMed: 22837916].

16. Fox S. The online health care revolution: How the web helps Americans Take better care of themselves. A Pew Internet and American Life Project Online Report. http://www.pewinternet. org/reports/pdfs/PIP_Health_Report pdf. 2000.

17. Praet SF, Van Loon LJ. Optimizing the therapeutic benefits of exercise in type 2 diabetes. Journal of applied physiology. 2007;103(4):1113-20. doi: 10.1152/japplphysiol.00566.2007. [PubMed: 17656625].

18. Bergman MM, Scott J. Young adolescents' wellbeing and health-risk behaviours: Gender and socio-economic differences. Journal of adolescence. 2001;24(2):183-97. doi: 10.1006/jado.2001.0378. [PubMed: 11437479].

19. Vosoghi KN, Abootalebi DG, Farahani B, Mohammadnezhad E, Sajjadi A. The study of self-care agency in patients with diabetes (Ardabil). 2012.

20. Barone B, Rodacki M, Zajdenverg L, Almeida M, Cabizuca C, Barreto D, et al. Family history of type 2 diabetes is increased in patients with type 1 diabetes. Diabetes research and clinical practice. 2008;82(1):e1-e4. doi: 10.1016/j.diabres.2008.03.015. [PubMed: 18835018].

21. Strauss A, Corbin JM. Grounded theory in practice: Sage; 1997.

22. Azkia M, Imani A. Theoretical analysis of land exploitation systems with an emphasis on pastures. Community Development (Rural and Urban Communities). 2012;3(2):1-28.

23. Shum J, Poureslami I, Wiebe D, Doyle-Waters MM, Nimmon L, FitzGerald JM, et al. Airway diseases and health literacy (HL) measurement tools: a systematic review to inform respiratory research and practice. Patient education and counseling. 2018;101(4):596-618. doi: 10.1016/j.pec.2017.10.011. [PubMed: 29107399].

24. Van de Vord R. Distance students and online research: Promoting information literacy through media literacy. The Internet and Higher Education. 2010;13(3):170-5. doi: 10.1016/j.iheduc.2010.03.001

25. Gaster L, Squires A. Providing quality in the public sector: a practical approach to improving public services: Public Policy and Management; 2003. 